\title{
Dobre, C. E. (2020). Max Picard. La filosofía como renacer espiritual. Gedisa. $140 \mathrm{pp}$.
}

El libro de la Dra. Catalina Elena Dobre, reconocida investigadora del pensamiento de Kierkegaard, así como de pensadores poco conocidos y referidos en el ámbito de la filosofía profesional, como Lev Shestov, Benjamin Fondane, Rahel Levin Varhagen o Emil M. Cioran, todos ellos pensadores y pensadoras del corazón al estilo de Blaise Pascal, presenta por primera vez para los lectores de habla hispana una apasionada y profunda comprensión de la obra y el pensamiento del médico y filósofo suizo, nacido en 1888 y fallecido en 1965, Max Picard. Admirado por su amigo Gabriel Marcel, quien lo consideraba uno de los pensadores más originales de nuestros tiempos, un metafísico del silencio o uno de los que desarrolla una original filosofía del rostro de la persona, que tanta influencia tuvo en Emmanuel Lévinas, Picard ha sido, sin embargo, olvidado e ignorado después del homenaje que Lévinas le rindió en un congreso en París en 1966 para ser retomado hasta el año 2009 en un congreso internacional en Turín gracias a la labor del filósofo Jean-Luc Egger.

La gran virtud del libro de la Dra. Dobre es evidenciar la profundidad de la vitalidad del pensamiento de Picard, desplegando cómo su expresión filosófico-poética, que puede parecer enigmática, es una composición de argumentos que trascienden la lógica de la enunciación para desposeer al conocimiento y sus formas técnicas, estratégicas o tecnológicas de poder. Porque el pensamiento y la expresión de Picard, como nos dice la Dra. Dobre, pretende ser un devenir del rostro de la persona como imagen de Dios, y esto solo sucede en el silencio, que no es un acto de callar, sino la única realidad de expresión metafísica en la cual la humildad, la generosidad y el amor se decantan configurando la vida desde su raíz y vocación para una relación singular auténtica.

La segunda gran virtud del libro de la Dra. Dobre es mostrar el universo de pensadores, artistas, escritores y poetas que fluyen en el pensar de Max Picard y que en sus propias obras casi nunca se ven referenciados de forma explícita, con lo cual nos ayuda a comprender a Picard en la sinfonía de la historia del pensamiento y de la cultura occidental. Entre ellos se denotan Søren Kierkegaard, Friedrich Nietzsche, Martin Heidegger, así como sus amigos, con los cuales se encontraba frecuentemente en su autoexilio en los Alpes suizos: Hermann Hesse, Gabriel Marcel, Thomas Mann, André Gide, Martin Buber, Romain 
Rolland y Rainer Maria Rilke, quien inclusive escribió un poema sobre Picard. Y la tercera virtud del libro de la Dra. Dobre es haber titulado los capítulos del libro en correspondencia con el nombre de las obras de Max Picard que aún esperan ser traducidas al español.

En el primer capítulo de los siete que componen el libro, El itinerario espiritual de Max Picard, la Dra. Dobre nos muestra a Picard como un peregrino que deja la profesión de médico para autoexiliarse entre los Alpes que dividen Suiza de Italia, pero no para alejarse del mundo, sino para encontrar su verdadero sentido, rodeándose de las mejores amistades de la cultura de aquellos tiempos. De tal forma que Picard entre las montañas y las amistades de los sabios lograron crear una contemplación activa sobre la plenitud de la encarnación del rostro humano como relación sagrada consigo mismo, la naturaleza, el mundo y Dios. Max Picard, nos expone la Dra. Dobre, tenía una profunda conciencia de que las crisis y catástrofes humanas que se avecinaban, no solo sobre Europa con las guerras mundiales, sino sobre la cosmovisión global del ser humano, se debían al alejarse y vaciarse de esta posibilidad de encarnación espiritual. Esto quiere decir que el acto fatal de la guerra no es la causa única, sino el modo en que los productos de esta se volvieron fundamentales y más importantes que la vida, los seres humanos y sus relaciones espirituales.

De ahí su crítica constante a la tecnología, a la indiferencia de los procesos políticos y sus ideologías, respecto de lo cual la Dra. Dobre agrega que podrían extenderse en nuestros días a las formas huecas del academicismo en los ámbitos universitarios. Por ello, en el segundo capítulo, Hacer filosofía al margen de la filosofía, la Dra. Dobre nos expone el modo, la vocación y el espíritu de hacer filosofía de Max Picard. Una filosofía, cuya expresión es poética, porque es una vocación espiritual que busca con incesante amor la unicidad de la encarnación de su propia singularidad, y porque requiere que sus lectores vivan el lenguaje como el vehículo de su propio devenir. Lo cual es un acto vital de resistencia contra nuestros tiempos, en los que utilizamos artificios desprovistos de devenir, de unidad, de sacralidad, para enmascarar nuestros narcisismos, resentimientos o impotencias de vivir, lo que para Picard nos llevo a fenómenos como los de Hitler, lo que expresó en su libro Hitler entre nosotros.

Esto lo desarrolla la Dra. Dobre en el tercer capítulo, "Hitler entre nosotros": la conciencia de la degradación humana. Para Picard, Hitler expresa real y simbólicamente la pérdida del rostro humano como la 
manifestación de la profundidad de las relaciones sagradas. Hitler es la hipocresía de la máscara, del odio, de la tristeza ante la vida que en su trivialidad desacraliza al mundo porque acaba con su memoria o con las huellas de esta, y de todo rastro de trascendencia personal que no sea la de subordinarse a la máquina militar de su voluntad: en pocas palabras, el narcisismo convertido en forma de vida política.

Después aparecen los dos capítulos centrales del libro: el cuarto, El rostro como imago dei. La manifestación del espíritu en el hombre, y el quinto, La metafísica del silencio, que refieren respectivamente a las obras de Picard El rostro humano y El mundo del silencio (prologado este último por Gabriel Marcel). El rostro es para Picard la singularidad de la persona, como lo es para Kierkegaard el devenir del individuo singular, relación que se indica en sus cartas con Gabriel Marcel. Por lo que no es individualismo, sino todo lo contrario, es la cristalización de la profundidad con la que cada persona es un ser relacional, dialógico y creativo, que se une y se potencia con el sentido sagrado de la existencia como una comunidad espiritual y, en última instancia, para Picard, con Dios. El rostro es la imagen como realidad participativa, nos dice la Dra. Dobre, que se expresa sobre todo con la mirada y donde reposan la humildad, lo sublime, la dignidad, el silencio, el amor y la claridad. Así, la Dra. Dobre logra inspirarnos profundamente el mensaje de Picard: que devenir auténticamente humanos es recuperar el origen sagrado del ser a través del rostro en el ámbito del silencio.

En su obra más conocida, El mundo del silencio, por la cual Gabriel Marcel lo considerará un "metafísico del silencio", Picard no se refiere al acto humano de callar, sino al ámbito siempre presente y activo, que une la forma de ser de todas las cosas. El intersticio musical en el que nos encontramos y nos toca ser parte, pero que requerimos de la adecuada atención para que resuene en nuestra concreta manifestación personal, y cuya característica fundamental es la trascendencia de la utilidad y de lo instrumental del lenguaje para revelar la unidad que no aniquila la diferencia particular, resonando en la propia personalidad.

El silencio es una realidad originaria de continuidad, apertura y presencia, que solo de modo superficial parece oponerse al lenguaje, es decir, en sus efectos, pero es, como ha dicho Alfonso López Quintás refiriendo a Max Picard, el entreveramiento o el adensamiento de la relacionalidad sustantiva, subsistente e inherente a todos los seres como creación viva de Dios. Así lo desarrolla la Dra. Dobre en el sexto capítulo, Hombre y lenguaje. El silencio es en realidad la causa o la condición sine 
qua non del lenguaje en todas sus formas y, por ende, de la comunicación humana como participación íntima con el devenir del propio corazón.

En el séptimo capítulo, La huida ante Dios. Una mirada crítica sobre la decadencia de la cultura moderna, y en el octavo, las conclusiones, la Dra. Dobre nos refiere que el rostro en Max Picard es la imagen de Dios que participa de la humildad, el amor y el perdón, que acontece en la oración como una elección fundamental, pero de cuya presencia los seres humanos vivimos constantemente huyendo, de su invitación y de su abrazo de ternura. Por lo cual, Dios se vuelve, al mismo tiempo, el que persigue por amor y el que espera por amor, y es entre esos dos ámbitos de la realidad divina que la filosofía adquiere su carácter fundamental: como forma de vida y renacer espiritual, pues, como nos dice al final la Dra. Dobre, "el mundo no puede ser destruido por el hombre, el hombre tiene la tarea de elegir su modo de ser: huir o existir con todo el profundo significado de lo que esto implica" (p. 132).

Rafael García Pavón Universidad Iberoamericana gclimacus71@gmail.com 